\title{
An increase of microRNA-16-1 is associated with the high proliferation of squamous intraepithelial lesions in the presence of the integrated state of HR-HPV in liquid cytology samples
}

\author{
MA ISABEL ZUBILLAGA-GUERRERO ${ }^{1}$, BERENICE ILLADES-AGUIAR ${ }^{2}$, EUGENIA FLORES-ALFARO ${ }^{3}$, \\ YANETH CASTRO-CORONEL ${ }^{1}$, HILDA JIMÉNEZ-WENCES ${ }^{4}$, ESTHER IVONNE LÓPEZ-BAYGHEN PATIÑO ${ }^{5}$, \\ KAREN ITZEL GARCÍA PÉREZ ${ }^{1}$ and LUZ DEL CARMEN ALARCÓN-ROMERO ${ }^{1}$
}

\begin{abstract}
${ }^{1}$ Laboratory for Research in Cytopathology and Histochemical; ${ }^{2}$ Laboratory for Molecular Biomedicine; ${ }^{3}$ Laboratory for Research in Clinical and Molecular Epidemiology; ${ }^{4}$ Laboratory for Research in Biomolecules, Faculty of Chemical-Biological Sciences, Autonomous University of Guerrero, Chilpancingo, Guerrero 39089; ${ }^{5}$ Department of Toxicology, Center for Research and Advanced Studies of the National Polytechnic Institute, Mexico City 07360, Mexico
\end{abstract}

Received November 7, 2018; Accepted July 22, 2020

DOI: 10.3892/ol.2020.11965

\begin{abstract}
Studies of cervical cancer (CC) have reported that microRNA-16-1 (miR-16-1), which is an oncomiR, is increased in the tissues and cell lines of CC. The aim of the present study was to investigate the association of miRNA-16-1 expression level with squamous cell carcinoma (SCC), the presence of squamous intraepithelial lesions (SIL) and the integration of high-risk human papillomavirus (HR-HPV) DNA. The current study analyzed 80 samples obtained from women by liquid-based cytology, which revealed that 20 were negative for SIL (NSIL) and without HPV, 20 were low-grade SIL (LSIL), 20 were high-grade SIL (HSIL), and 20 were diagnosed as SCC with HR-HPV. The genotyping of the viral DNA was conducted via an INNO-LiPA-HPV array, the expression of miR-16-1 was determined by reverse transcription-quantitative PCR, and the physical state of the HR-HPV was ascertained by in situ hybridization with amplification with tyramide. A total of eight HR-HPV genotypes were distinguished; the most frequent of these being HPV16, followed by multiple infection with HR-HPV (including HPV16). The mixed state of the HR-HPV was observed in 60 and $65 \%$ of LSIL and HSIL cases, respectively, while an integrated HR-HPV state was identified in $90 \%$ of cases with SCC. The expression level of miR-16-1 increased according to the grade of SIL, and cases with HSIL exhibited a significantly higher miR-16-1
\end{abstract}

Correspondence to: Dr Luz Del Carmen Alarcón-Romero, Laboratory for Research in Cytopathology and Histochemical, Faculty of Chemical-Biological Sciences, Autonomous University of Guerrero, Avenue Lázaro Cárdenas s/n, Chilpancingo, Guerrero 39089, Mexico E-mail: 1calarcon@uagro.mx

Key words: microRNA-16-1, high-risk human papillomavirus, low-grade squamous intraepithelial lesion, high-grade squamous intraepithelial lesion, squamous cell carcinoma expression level compared with women with NSIL $(\mathrm{P}<0.001$; Table II). It can therefore be determined that the expression of miR-16-1 effects cellular proliferation, due to the viral integration of various HR-HPV genotypes in unique infection or in multiple infection. Thus, the overexpression of miR-16-1 could be monitored in women with LSIL, in order to discard a major lesion.

\section{Introduction}

Cervical cancer (CC) represents the fourth highest cause of mortality in the female population worldwide, with $\sim 569,847$ newly diagnosed CC cases and 2311,365 CC-associated deaths in 2018 (1). The most prevalent histological subtypes are squamous cell carcinoma (SCC) and adenocarcinoma (AC), with SCC representing $\sim 70 \%$ of CC cases (2). Persistent infection associated with high-risk human papillomavirus (HR-HPV) is considered to be a key risk factor in the development of CC, particularly HPV types 16 and 18 (3). Additionally, the integration of HR-HPV DNA in fragile host-genome sites, favors the overexpression of oncoproteins E6 and E7. This, as a result, promotes the progression and transformation of malignant cells, inducing genetic and epigenetic instability (4).

From the cytological point of view, the Bethesda system classifies precursor lesions of $\mathrm{CC}$ as low-grade squamous intraepithelial lesions (LSIL) and high-grade lesions (HSIL). LSIL are characterized by the presence of cells with karyomegaly, perinuclear halo and binucleation (koilocytes), while HSIL is associated with the presence of intense binucleation and dyskaryosis in basal and parabasal cells with little cytoplasm, hyperchromatic and big nuclei. Furthermore, SCC is characterized by large undifferentiated and multinucleated cells lacking cytoplasm, pleomorphic nuclei and irregular distribution of chromatin (5).

Integration of HR-HPV, in addition to altering significant transcription patterns and regulating the expression of E6 and E7, also regulates the expression of host genes in fragile 
integration sites (6). It is important to note that a number of these genes have an oncogenic function, for example as oncogenic microRNAs (miRNAs/miRs) (7). miRNAs suppress genetic translation by binding to the 3'-untranslated region of their target genes (8). Previous studies have shown that numerous miRNAs are implicated in CC, such as miR-16-1 (9), miR-21 (10), miR-22-3p (11) and miR-486-5p (12). These miRNAs contribute to a number of cellular processes, such as cell proliferation $(9-12)$, invasion $(9,10,12)$, migration (12) and apoptosis (11).

miR-16-1 is a regulator of gene expression at the posttranscriptional level. Studies have reported that miRNAs are often increased in certain cancer types, including breast cancer (13), hepatocellular carcinoma (14) and CC (9,15-20). miR-15a and miR-16-1 form part of a cluster in an intron region of the deleted in lymphocytic leukemia 2 (DLEU2) transcript on chromosome $13 \mathrm{q} 14.3$, which is frequently deleted in chronic lymphocytic leukemia. Both are implicated in cellular invasion, survival and proliferation (21).

It has been reported that the expression of miR-16-1 is decreased in CC cell lines that are positive for HPV16 and HPV18 following transfection with a siRNA for oncoprotein E7, suggesting that the increase in miR-16-1 expression may be due to the E7/E2F/miR-16-1 pathway (22). Furthermore, other studies have indicated that miR-16-1 possesses an oncomiR function in CC $(15-18,20)$. The overexpression of miR-16-1 is associated with activation of genes implicated in the cell cycle, including CDK6, CDC27, CARD10, C10orf46 (23) and CCNE1 (9), which promote the proliferation of cancerous cells. The aim of the present study was to investigate the association of the miR-16-1 expression level with squamous intraepithelial lesions (SIL) and with the integration of HR-HPV DNA.

\section{Materials and methods}

Participants and sample collection. The present study included 80 liquid-based cytology samples obtained from the squamous-column transformation zone (TZ) of the uterine cervix of female patients aged 18-71 years, who resided within the State of Guerrero, Mexico. The mean age was 42 years. Between March 2012 and September 2018, the patients presented at the Integral Diagnostic Service for the Timely Detection of Cervical Cancer and HPV of the Autonomous University of Guerrero (Chilpancingo, Mexico), to the Dysplasia Clinic of the General Hospital 'Raymundo Abarca Alarcón' (Chilpancingo, Mexico) and to the State Institute of Cancerology 'Arturo Beltrán Ortega' (Acapulco, Mexico).

The study was approved by the Ethics Committee of the Autonomous University of Guerrero, Guerrero, Mexico. All patients signed an informed consent for the use of their cervical samples and clinical information. This study was also performed according to the ethical guidelines of the Declaration of Helsinki 2008 (24).

Cytological examinations, HPV genotyping and measurements of miR-16-1 by reverse transcription-quantitative PCR (RT-qPCR) were performed in the present study. Three ectocervical and three endocervical samples were obtained from each patient, utilizing an Ayre spatula (ectocervix) and cytobrush (endocervix), ensuring cytological material was from the $\mathrm{TZ}$ of the uterine cervix. The cytological diagnosis was performed by a cytotechnologist (LdCA-R) who was accredited and certified by the Mexican Council of Technicians in Pathobiology, A.C., and the Mexican Council of Anatomopathological Physicians, A.C., with 29 years of experience, utilizing the criteria of the Bethesda System (5). The colposcopic diagnosis was performed by the colposcopist Dr Raúl Peralta-Catalán responsible for the Dysplasia Clinic of the General Hospital 'Raymundo Abarca Alarcón' (Chilpancingo, Mexico). The histopathological diagnosis, for confirmation of SIL and SCC, was performed by the pathologist Marco Antonio Jiménez-López at the State Institute of Cancerology ‘Arturo Beltrán Ortega' (Acapulco, Mexico) (25).

Cytological examination. Slides with the cytological smears of the $\mathrm{TZ}$ for conventional cytology examination were fixed in ethanol for $10 \mathrm{~min}$. The slides were then stained using the Papanicolaou kit (cat. no. 64294; Hycel, Chemical Reagents). Briefly, the slides were hydrated in a descending alcohol series and then incubated at room temperature for $45 \mathrm{sec}$ with Harris hematoxylin to stain the nuclei. Additionally, Orange G colorant was added and incubated at room temperature for $80 \mathrm{sec}$, followed by EA-50 incubated at room temperature for $3 \mathrm{~min}$, which stained the eosinophils and basophils cells, respectively. The slides were then cleared with Xylol reagent prior to microscopic observation (DM1000 LED; Leica Microsystems, Inc.; magnification, x10-x20).

Alternatively, the samples for liquid-based cytology were processed according to the manufacturer's protocol of liquid-PREP ${ }^{\mathrm{TM}}$ (LGM International, Inc.). Briefly, a clearing solution was added to each sample and then the samples were centrifuged at $1,000 \mathrm{x}$ g for $5 \mathrm{~min}$ at room temperature. The supernatant was discarded after the addition of the cell base solution, which conserved the pellet. The samples were mixed and $10 \mu \mathrm{l}$ was added to a slide, which was fixed at room temperature with ethanol for $10 \mathrm{~min}$, following by staining using Papanicolaou kit and microscopic observation (DM1000 LED; Leica Microsystems, Inc.; magnification, x10-x20).

Genotyping and the physical state of HR-HPV. Using cervical cytology samples in PBS (pH 7.0), DNA was extracted by the standard method of phenol-chloroform extraction (26). For HPV genotyping, the reverse INNO-LiPA Genotyping Extra assay (Invitrogen; Thermo Fisher Scientific, Inc.) was used according to the manufacturer's instructions. This method allowed the simultaneous identification of 28 different HPV genotypes. Briefly, the L1 region of HPV was PCR-amplified with the SPF10 primers. The biotinylated amplicons were denatured and hybridized with specific and immobile oligonucleotides anchored to a membrane, and then Streptavidin conjugated with alkaline phosphatase was added, followed by Chromogen BCIP/NBT to reveal the reaction. The HLA-DPB1 gene was employed as a control for DNA amplification, and the L1 region of HPV6 was utilized as a positive control.

The determination of the physical state of viral DNA was performed by means of the Dako GenPoint ${ }^{\mathrm{TM}}$ Tyramide Signal Amplification System for Biotinylated Probes (Agilent Technologies, Inc.), according to the manufacturer's protocol. Briefly, liquid-based cytology smears were submitted to permeabilization for $30 \mathrm{~min}$ at $120^{\circ} \mathrm{C}$, followed by enzymatic digestion for $5 \mathrm{sec}$ with $\mathrm{K}$ proteinase $(1: 1,000)$. The samples 
were then added to $1 \mu \mathrm{l}$ test reagent (Dako GentPoint ${ }^{\mathrm{TM}} \mathrm{HPV}$ DNA Probe Cocktail, Biotinylated) for 13 HR-HPV genotypes $(16,18,31,33,35,39,45,51,52,56,58,59$ and 68; Agilent Technologies, Inc.). The slides were subjected to DNA denaturation for $10 \mathrm{~min}$ at $95^{\circ} \mathrm{C}$ and hybridization for $20 \mathrm{~h}$ at $37^{\circ} \mathrm{C}$ on a Dako Hybridizer (Agilent Technologies, Inc.). Subsequently, the slides were placed in an astringent solution $(1: 20)$ for $20 \mathrm{~min}$ at $55^{\circ} \mathrm{C}$, followed by the addition of $30 \mu \mathrm{l}$ primary streptavidin-HRP conjugate (1:50) for $1 \mathrm{~h}$ and incubation in a humidified chamber at room temperature. Subsequently, $30 \mu \mathrm{l}$ biotinyl tyramide was added for $40 \mathrm{~min}$ and $30 \mu \mathrm{l}$ secondary streptavidin-HRP conjugate was added for $1 \mathrm{~h}$ in a humidified chamber at room temperature. Diaminobenzidine (1:20) was then added for $10 \mathrm{sec}$, followed by counterstaining with Harris hematoxylin (Merck KGaA) for $10 \mathrm{sec}$, both incubations at room temperature. The positive reaction with the nucleus was identified by a brown color, which was classified as diffuse (episomal state), punctate (integrated state) or mixed (episomal and integrated state). As a positive control, the $\mathrm{SiHa}$ cervical cancer cell line (catalog no. HTB-35; American Type Culture Collection) was used and, as negative control, $\mathrm{SiHa}$ cells were used without the test reagent. The cell line was cultivated in DMEM (Invitrogen; Thermo Fisher Scientific, Inc.) supplemented with $10 \%$ FBS (Merck KGaA), $50 \mu \mathrm{g} / \mathrm{ml}$ penicillin/streptomycin (Merck KGaA), 2 mM L-glutamine (Merck KGaA) and $250 \mathrm{ng} / \mathrm{ml}$ fungizone (Merck KGaA), and placed at $37^{\circ} \mathrm{C}$ in a humidified incubator containing $5 \% \mathrm{CO}_{2}$.

Analysis of miR-16-1 expression. Using the cervical cytology samples, total RNA was extracted using TRIzol ${ }^{\circledR}$ Reagent (Thermo Fisher Scientific, Inc.), according to the manufacturer's protocol. Briefly, $1 \mathrm{ml} \mathrm{TRIzol}{ }^{\circledR}$ Reagent was added to each sample and incubated for 5 min to permit the dissociation of the nucleus-protein complex. Subsequently, $200 \mu \mathrm{l}$ chloroform for every $1 \mathrm{ml}$ TRIzol ${ }^{\circledR}$ Reagent was added, followed by vigorous shaking for $15 \mathrm{sec}$ and incubation for $3 \mathrm{~min}$. Following incubation, the sample was centrifuged at $12,000 \mathrm{x} \mathrm{g}$ at $4^{\circ} \mathrm{C}$ for $5 \mathrm{~min}$. The aqueous phase, which contains the RNA, was transferred into a new tube. Next, $500 \mu \mathrm{l}$ isopropanol per $1 \mathrm{ml} \mathrm{TRIzol}{ }^{\circledR}$ Reagent was used for lysis for $10 \mathrm{~min}$ at $-70^{\circ} \mathrm{C}$, followed by centrifugation at $14,000 \mathrm{x} \mathrm{g}$ at $4^{\circ} \mathrm{C}$ for $15 \mathrm{~min}$. The supernatant was then discarded and the sediment was re-suspended in $20 \mu \mathrm{l}$ RNase-free water. The concentration of RNA was evaluated by UV absorbance at $260 \mathrm{~nm}$ (A260) using a Thermo Scientific NanoDrop 200c (Thermo Fisher Scientific, Inc.). Synthesis of the complementary DNA (cDNA) was carried out using the TaqMan MicroRNA Reverse Transcription kit (Thermo Fisher Scientific, Inc.), which possesses a high capacity for synthesizing cDNA from miRNA. In total, $5 \mathrm{ng}$ total RNA was utilized for synthesizing the cDNA of the miR-16-1. Briefly, inverse transcription assays were prepared with $3 \mu \mathrm{l}$ 5X RT primer, $5 \mu 1$ RNA sample and $7 \mu 1$ Master mix [100 mM dNTPs (with dTTP) $(0.15 \mu \mathrm{l})$, MultiScribe ${ }^{\mathrm{TM}}$ Reverse Transcriptase (50 U/ $\mu 1 ; 1 \mu \mathrm{l}), 10 \mathrm{X}$ Reverse Transcription Buffer $(1.50 \mu \mathrm{l})$, RNAse Inhibitor $(20 \mathrm{U} / \mu \mathrm{l} ; 0.19 \mu \mathrm{l})$ and Nuclease-Free water $(4.16 \mu \mathrm{l})$ in a total volume of $15 \mu \mathrm{l}]$. The reactions were incubated in an Eppendorf thermocycler (Eppendorf Mastercycler EP Gradient Model 5341) for $30 \mathrm{~min}$ at $16^{\circ} \mathrm{C}, 30 \mathrm{~min}$ at $42^{\circ} \mathrm{C}$, and $5 \mathrm{~min}$ at $85^{\circ} \mathrm{C}$, followed by storage at $4^{\circ} \mathrm{C}$ until later use.
Table I. HR-HPV state according to cytological diagnosis.

\begin{tabular}{lccc}
\hline & \multicolumn{3}{c}{ Diagnosis } \\
\cline { 2 - 4 } HR-HPV state & LSIL, n (\%) & HSIL, n (\%) & SCC, n (\%) \\
\hline Integrated & $8(40)$ & $7(35)$ & $18(90)$ \\
Mixed & $12(60)$ & $13(65)$ & $2(10)$ \\
Total & $20(100)$ & $20(100)$ & $20(100)$ \\
\hline
\end{tabular}

HR-HPV, high-risk human papillomavirus; LSIL, low-grade squamous intraepithelial lesions; HSIL, high-grade squamous intraepithelial lesions; SCC, squamous cell carcinoma.

The PCR reaction was conducted at $95^{\circ} \mathrm{C}$ for $10 \mathrm{~min}$ followed by 40 cycles at $95^{\circ} \mathrm{C}$ for $10 \mathrm{sec}$ and at $60^{\circ} \mathrm{C}$ for $60 \mathrm{sec}$ using TaqMan $^{\mathrm{TM}}$ MicroRNA Assays (Thermo Fisher Scientific, Inc.). Specific primers (Thermo Fisher Scientific, Inc.) were used for hsa-miR-16-1 (5'-UAGCAGCACGUAAAUAUUGGCG-3') and RNU44 (5'-CCTGGATGATGATAGCAAATGCTGACTGAA CATGAAGGTCTTAATTAGCTCTAACTGACT-3'), which was used for normalization. The reaction was incubated in PCR tubes and caps, RNase-free, $0.2 \mathrm{ml}$ (catalog no. AM12230; Thermo Fisher Scientific, Inc.) in the CFX96 Touch $^{\mathrm{TM}}$ Real-Time PCR Detection system supplied with analytical software (Bio-Rad Laboratories, Inc.). Each reaction was performed in triplicate. The $2^{-\Delta \Delta C T}$ method (27) was employed to evaluate the relative abundance of miR-16-1 compared with the expression of RNU44, which is a small nuclear RNA and is one of the 18 human endogenous controls identified as the most abundant in all tissues, based on $\mathrm{C}_{\mathrm{T}}$ averages (22-28.9), good linearity test $\left(\mathrm{R}^{2}>0.96\right)$ and its relatively stable expression (28).

Statistical analysis. Data are presented as frequencies for the qualitative variables and as the mean \pm standard error for quantitative variables. One-way analysis of variance followed by Bonferroni's post hoc test was used to compare the expression level of miR-16-1 between study groups. The association of cytological diagnosis or the physical state of the HPV with the expression level of miR-16-1 was evaluated through linear regression models. This obtained the regression coefficients $(\beta)$, as the average change in the expression of miR-16-1 by cytological diagnosis or physical state of the HPV, in comparison with the reference category (NSIL). $\mathrm{P}<0.05$ was considered to indicate a statistically significant difference. Statistical analysis was performed using STATA V.13 statistical software (StataCorp LLC).

\section{Results}

Genotypes and physical state of the HPV. Once the cytological results were obtained, the following cytological samples of women were selected as follows: 20 samples with negative diagnosis for SIL and without HPV infection; 20 samples with LSIL; 20 samples with HSIL (of which $45 \%$ were diagnosed with carcinoma in situ); and 20 samples with SCC. Women with SIL or SCC had HR-HPV infection. From the findings of the present study, eight types of HR-HPV could be identified; 

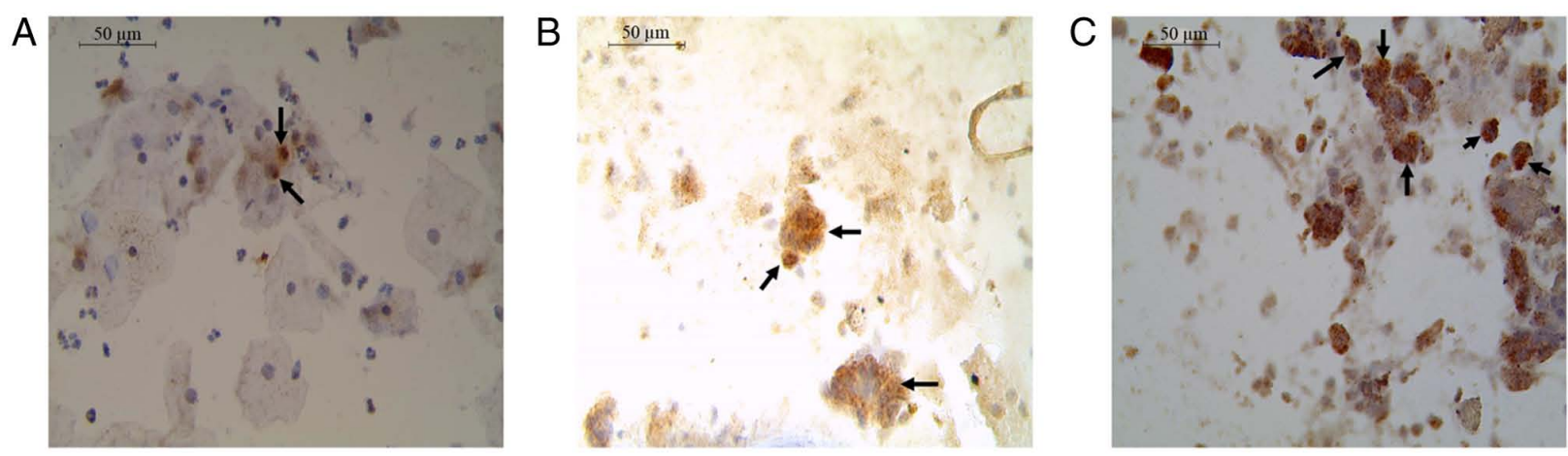

Figure 1. Physical state of the HR-HPV according to the grade of squamous intraepithelial lesions and SCC. (A) Integrated state (black arrows) of the genome of HPV16 in cells with karyomegaly with hyperchromatic nuclei in a case of low-grade squamous intraepithelial lesions. (B) Integrated state (black arrows) of HPV16 DNA in groups of cells with intense dyskaryosis, in basal and parabasal cells with big and hyperchromatic nuclei, compatible with a high-grade squamous intraepithelial lesions. (C) Integrated state (black arrows) of HPV16 DNA in a case of SCC in undifferentiated cells with irregular chromatin distribution in pleomorphic nuclei (Magnification, x40). HR-HPV, high-risk human papillomavirus; SCC, squamous cell carcinoma.
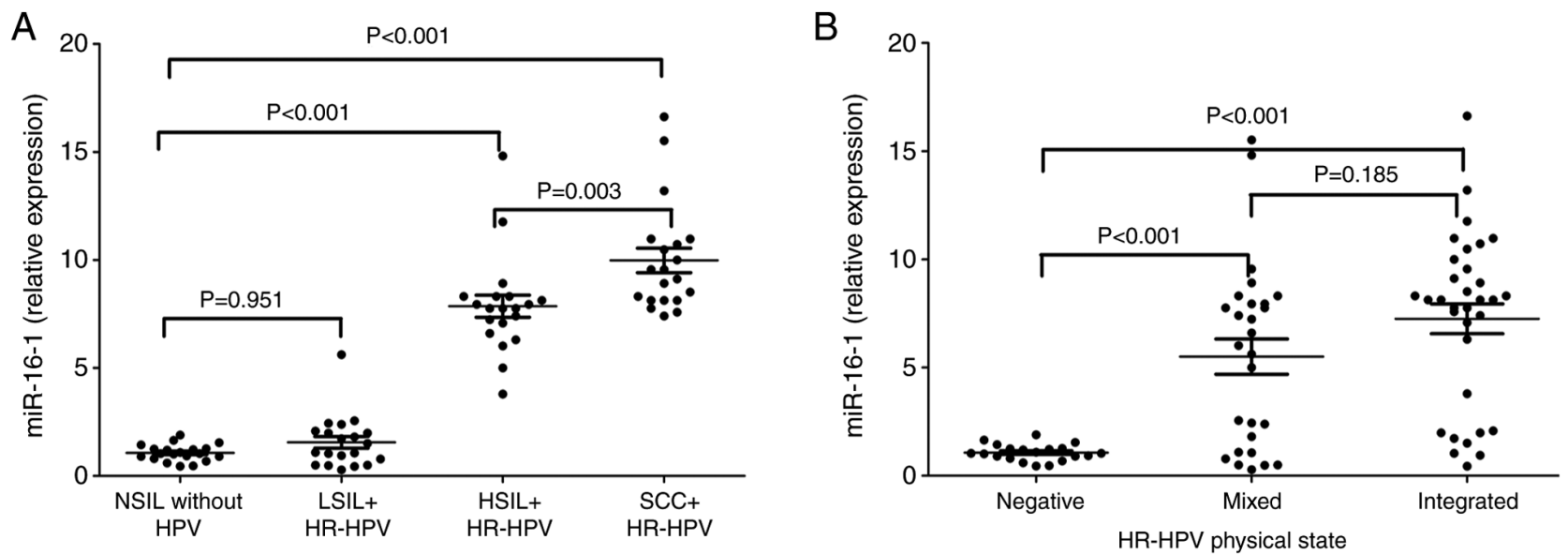

Figure 2. RT-qPCR of the expression of miR-16-1. The relative expression of miR-16-1 was assessed by RT-qPCR and the 2- $\Delta \Delta \mathrm{CT}$ method. The relative expression of miR-16-1 was compared between the study groups and the different physical states of HR-HPV using the ANOVA. (A) Significant increase in miR-16-1 expression is identified in HSIL and SCC compared with NSIL $(\mathrm{P}<0.001)$ and an increase in SCC compared to HSIL ( $\mathrm{P}=0.003)$. (B) Expression of miR-16-1 was significantly increased in the mixed $(\mathrm{P}<0.001)$ and integrated $(\mathrm{P}<0.001)$ physical state compared with the negative samples. RT-qPCR, reverse transcription-quantitative PCR; miR-16-1, microRNA-16-1; HR-HPV, high-risk human papillomavirus; NSIL, negative for squamous intraepithelial lesions; LSIL, low-grade squamous intraepithelial lesions; HSIL, high-grade squamous intraepithelial lesions; SCC, squamous cell carcinoma.

the most frequent being $16,18,31,33,45,51,52$ and 58 . The frequency of HPV16, in relation to the cytological diagnosis, was $20 \%$ in LSIL, $30 \%$ in HSIL and $40 \%$ in SCC. Notably, $15 \%$ of LSIL, $20 \%$ of HSIL, and $40 \%$ of SCC presented with multiple infection (MI) with the genotypes of HR-HPV, including HPV16 (data not shown). On the other hand, it is important to note that when analyzing the physical state of the HR-HPV DNA, an integrated state was identified in $40 \%$ of women with LSIL, in $35 \%$ of women with HSIL and in $90 \%$ of women with SCC (Table I). Cytologically in the LSIL cases, some intermediate cells with karyomegaly, binucleation, perinuclear halo and hyperchromatic nuclei were observed. These are considered to be characteristics of the HPV infection. The intermediate cells with karyomegaly presented 1-2 viral copies integrated (Fig. 1A). While in cytologies with HSIL, small groups of cells with moderate to intense dyskaryosis and binucleation were observed, in immature basal and parabasal cells with little cytoplasm, big and hyperchromatic nuclei. These cells presented multiple integrated copies (Fig. 1B). Finally, in the cases of SCC, multiple integrated copies were observed in large undifferentiated cells, multinucleated, devoid of cytoplasm, pleomorphic nuclei and irregular distribution of chromatin (Fig. 1C).

Expression of $m i R-16-1$. It was demonstrated that the mean expression level of miR-16-1 was increased significantly in women with HSIL $(7.9 \pm 0.5)$ and SCC $(10 \pm 0.6)$, in comparison with women with NSIL or LSIL $(\mathrm{P}<0.001)$. Although a small increase was identified in the expression of miR-16-1 in patients with LSIL $(1.6 \pm 0.3)$ in comparison with women with NSIL (1.1 \pm 0.1$)$, this was not statistically significant $(\mathrm{P}=0.95$; Fig. 2A). Linear regression analysis revealed a significant increase in the expression of miR-16-1 in women with HSIL $(\beta=6.8 ; \mathrm{P}<0.001)$ and in women with $\operatorname{SCC}(\beta=8.9 ; \mathrm{P}<0.001)$ in comparison with women NSIL, with an explanation percentage of $83 \%$ (Table II).

Additionally, significant differences were identified for the expression level of miR-16-1 in the samples with a mixed or integrated HPV physical state compared with the samples that did not present with HPV infection $(\mathrm{P}<0.001$; Fig. $2 \mathrm{~B})$. In 
Table II. Associations of the cytological diagnosis or physical state of HPV with the expression level of miR-16-1.

\begin{tabular}{|c|c|c|c|c|}
\hline Variable & Relative miR-16-1 expression, REU ${ }^{\mathrm{a}}$ & $\beta(95 \% \mathrm{CI})^{\mathrm{b}}$ & P-value & $\mathrm{r}^{2}$ \\
\hline \multicolumn{5}{|l|}{ Diagnosis } \\
\hline NSIL & $1.1 \pm 0.1$ & Ref. & & 0.83 \\
\hline LSIL & $1.6 \pm 0.3$ & $0.5(-0.7-1.6)$ & 0.395 & \\
\hline HSIL & $7.9 \pm 0.5$ & $6.8(5.6-7.9)$ & $<0.001$ & \\
\hline $\mathrm{SCC}$ & $10.0 \pm 0.6$ & $8.9(7.8-10.0)$ & $<0.001$ & \\
\hline \multicolumn{5}{|c|}{ Physical HPV state } \\
\hline Negative & $1.1 \pm 0.1$ & Ref. & & 0.33 \\
\hline Mixed & $5.5 \pm 0.8$ & $4.4(2.3-6.5)$ & $<0.001$ & \\
\hline Integrated & $7.3 \pm 0.7$ & $6.2(4.2-8.2)$ & $<0.001$ & \\
\hline \multicolumn{5}{|l|}{ Mixed } \\
\hline Integrated $^{c}$ & & Ref. $1.7(-0.4-3.9)$ & 0.105 & 0.04 \\
\hline
\end{tabular}
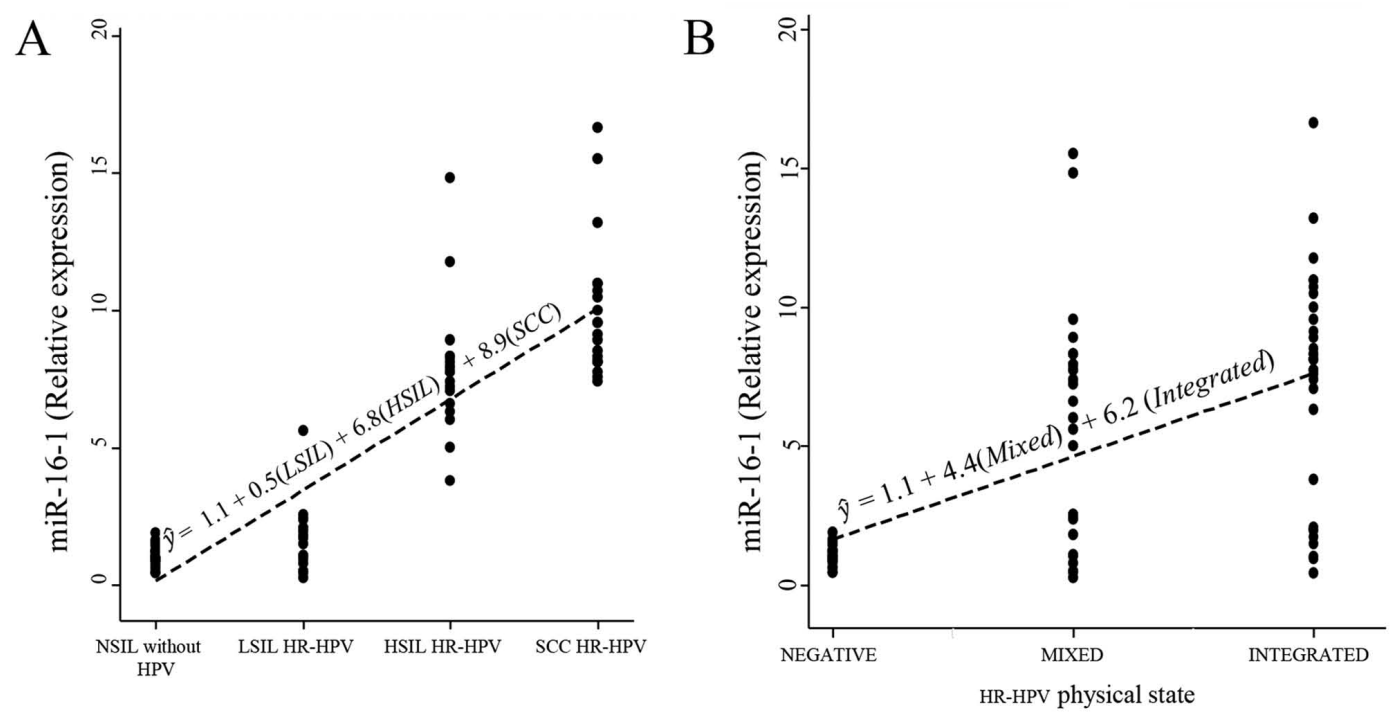

Figure 3. Effect of squamous intraepithelial lesions, squamous cell carcinoma and the physical state of HPV on the increase in the expression levels of miR-16-1. (A) The increase in the expression of miR-16-1 is associated with the progression of SIL to SCC. (B) There is no different effect on miR-16-1 overexpression between mixed and integrated HPV physical state. miR-16-1, microRNA-16-1; HR-HPV, high-risk human papillomavirus; NSIL, negative for squamous intraepithelial lesions; LSIL, low-grade squamous intraepithelial lesions; HSIL, high-grade squamous intraepithelial lesions; SCC, squamous cell carcinoma.

addition, a significant influence of the mixed $(\beta=4.4 ; \mathrm{P}<0.001)$ or integrated $(\beta=6.2 ; \mathrm{P}<0.001)$ state on the expression level of miR-16-1 ( $\mathrm{P}<0.001)$ was identified, compared with the samples negative for HPV infection; with an explanation percentage of $33 \%$. It is also important to comment that any relevant changes were not identified in the level of expression of miR-16-1 between the integrated physical state and the mixed state ( $\beta=1.7 ; \mathrm{P}=0.105$; Table II; Fig. 3).

\section{Discussion}

CC represents a serious public-health problem. Despite it being a preventable disease, it has high rates of incidence and mortality in developing countries, and in Mexico, $\mathrm{CC}$ is the third most common cancer in women with 7,689 new cases reported in 2018 (1). In Mexico, a nationwide cytology-based cervical cancer screening program was implemented in 1974, but the subsequent decrease in incidence and mortality have been modest (29). In Guerrero, Mexico, from the 2000 to 2013, $\mathrm{CC}$ represented the second most common cancer in women, which therefore makes $\mathrm{CC}$ the fifth highest contributor to mortality rates nationally (30). In Guerrero, Mexico, HPV16 has been identified as the most frequent genotype in $\mathrm{CC}$, followed by HPV18 (31). It is important to note that our group has previously reported that, in the state of Guerrero, there are five circulating variants of E6 of HPV16 (E-G350, AA-a, 
AA-c, E-C188/G350 and E-A176/G350). These variants have been associated with the development of SCC, and the AA-a variant has the greatest association with the development of CC (odds ratio, 69.01; confidence interval, 7.57-628.96) in comparison with the E-prototype variant (32).

In the present study, women diagnosed with LSIL, as well as women diagnosed with HSIL, presented with HPV16 with greater frequency in unique infection or MI compared with other types of HR-HPV. It has been noted that genotypes 16 and 18 are present in $>70 \%$ of SCC cases (3). A number of studies have reported that MI with HR-HPV can increase the risk of cervical intraepithelial neoplasia (CIN) progressing to SCC (33-35). However, other reports that HPV16, in itself, can increase the risk of developing a HSIL should also be considered (36).

Integration of viral DNA occurs because of chromosomal instability, which is induced by the aberrant expression of oncoproteins E6 and E7 (37). The biotinyl-tyramide-based in situ hybridization (ISH) amplification method has the advantage of allowing the in situ examination of the physical state of HPV DNA, preserving the morphology of the cells or tissues, as well as it being optimized to enable the reproducible detection of one to two integrated copies of the HPV-16 (38-40). It has been reported that in cervical scrapes or biopsy samples positive for HPV16 or 18 from 187 female patients without SIL, LSIL, HSIL and CC, ISH has a high concordance (96.1\%) with qPCR to determine the physical state of HPV. These results suggest that ISH has good concordance with qPCR with regards to the detection of HPV integration. Therefore, this method can be used for determining the physical status of HPV (41). The present study identified that women with LSIL (60\%), with HSIL (65\%) and with SCC (10\%) had principally a mixed state. In this regard, we reported previously that the mixed state of HR-HPV can be found in cytologies with LSIL with HR-HPV (42), while other investigators have reported it in HSIL (43). On the other hand, with respect to the integration of viral DNA, it was identified that $40 \%$ of LSIL, $35 \%$ of HSIL and $90 \%$ of women with SCC had viral integration. In our work group and with regards to previous studies, it was identified that in women with LSIL with HR-HPV, $10 \%$ had viral DNA integration (42), while some studies have reported that viral integration is an indicator of HSIL (44), and a predictive indicator that is markedly unfavorable for the survival of patients with primary $\mathrm{CC}$, in comparison with mixed forms of HR-HPV (45). One possible reason why the percentage of women with viral integration was similar between LSIL and HSIL is that in both study groups, HPV16 and 18 were present in single or multiple infection with other HR-HPV (data not shown). However, differences in the number of copies integrated between both groups were observed (Fig. 1). It is important to note that in LSIL the number of altered cells is lower compared with HSIL. In addition, it has been reported that viral integration in SIL and CC is more frequently related to HPV16, 18 and 58 genotypes $(41,46)$.

It must be considered that previous reports have demonstrated that viral integration is an early event in the progression of the disease $(47,48)$. In addition, it has been reported that populations of cells with integrated HPV16 possess a selective advance in growth, compared with cells that maintain episomal HPV16 genomes (49). The present study identified that the number of cells and the integrated copies in them increased in cytologies with HSIL and SCC compared with cytologies with LSIL (Fig. 1A-C). These results are important since it has been reported that those cells with multiple integrated copies of HPV16 has an increase in methylation patterns in the upstream regulatory region (URR) region of the viral genome, compared with those with only 1-2 integrated copies or those that present only episomal copies. This suggests that methylation in E2 binding sites, in the URR region of HPV16, can lead to deregulation of E6 and E7 expression in early stages of cell transformation induced by HR-HPV (50).

Furthermore, a wide range of studies have reported that miRNAs serve an important role in the regulation of gene expression, and the deregulation of miRNAs plays an important role in the development of human cancers (51). The expression of miR-16-1 is of great interest for further analysis, as it has been reported to be increased in a variety of human cancers, in which its function has been described as an oncomiR $(9,15-20,22)$. The present study did not identify significant differences in the expression of miR-16-1 between women who presented with NSIL and without HPV with those who presented with LSIL with HR-HPV $(\mathrm{P}=0.951)$. One limitation of the present study that must be considered when examining the results was the small sample size used to identify significant differences between these two groups. However, we found that HSIL, SCC or HPV physical state had an effect on the increase in miR-16-1 expression. The patients with HSIL and SCC with HR-HPV exhibited a significant increase in the expression of miR-16-1 in comparison with women with NSIL without HPV $(\mathrm{P}<0.001$; Table II). There are studies that have evaluated this miRNA in cell lines and tissues with SCC, for example. miR-16-1 was increased in 19 SCC tissue samples, 7 adenocarcinomas, 2 adenosquamous cell carcinomas and 2 small-cell carcinomas, all of these with HR-HPV, in comparison with normal tissue (15). Furthermore, an increase was found in the expression of miR-16-1 in ten tissues with invasive SCC in comparison with normal tissue according to RT-qPCR (16). Through Northern blot analysis, it has also been demonstrated that the expression of miR-16-1 is increased in cell lines with HPV and in CC tissues in comparison with normal tissue (17). Through microarrays, the expression of diverse miRNAs has been studied, and results demonstrated that the expression of miR-16-1 increased according to the grade of CIN, with higher expression observed in cases with CIN III and SCC, in comparison with CIN I and normal tissue (18). By contrast, through RT-qPCR, it was identified that the expression of miR-16-1 was lower in ten normal tissues was compared with 18 cases of CIN II and CIN III, 9 cases of adenocarcinoma and 10 cases of SCC, in which the expression increased according to the grade of CIN (19). Similar results were confirmed in a study in which the expression of miR-16-1 was higher in CIN I, CIN II, CIN III and CC in comparison with normal tissue (20).

In the present study, a basal expression of miRNA-16-1 was found in samples without SIL that were negative for HPV. It has been reported that the normal function of miR-16-1 is to negatively regulate the progression of the cell cycle, by regulating cell targets, such as CDK1, CDK2, CDK6, cyclin D1, cyclin D3 and cyclin E1 (52). In addition, during the progression of the normal cell cycle, the endogenous inactivation of E2F leads to an increase in the basal expression of miR-16-1 
and miR-15, and consequently the arrest of the cell cycle occurs in the G1 phase (53). The expression of miR-16-1 is increased in tissues of CIN I, CIN II, CIN III and CC compared with in normal tissue (20). Further studies have shown that when HR-HPV infection is present, the oncoprotein E7 dissociates the $\mathrm{RB} / \mathrm{E} 2 \mathrm{~F}$ complex, resulting in the endogenous activation of E2F $(54,55)$. By in silico analysis, it has been reported that the promoter of the human gene DLEU2 contains a binding site conserved for E2F in the position -4 to +4 ; therefore, the expression of miR-16-1 is endogenously regulated by E2F (53). These findings are important because cyclin E1 plays a crucial role in the transition of the G1/S phase, and it is known that this cyclin is transcriptionally regulated by E2F (56) and post-transcriptionally regulated by miR-16-1 $(9,57)$. These two molecular alterations can cooperate during tumor development, maintaining an increased proliferation of transformed cells.

It is noteworthy that the increased expression of miR-16-1 was mainly related to HSIL and SCC in 6.8 and 8.9 relative expression units, respectively, compared with NSIL (Table II). In this regard, the viral genome is replicated as episomal DNA during productive infections, while viral integration in the host chromosome by the HR-HPV has been associated with the progression of SIL to SCC (58). Deletion of the E2 gene results in the loss of negative regulation of the transcription of oncogenes E6 and E7, favoring dyscontrolled cellular proliferation and immortalization (59). Having found an increased expression in LSIL $(1.6 \pm 0.3)$, in comparison with normal samples $(1.1 \pm 0.1)$, it can be suggested that these cells possess a high proliferative capacity and that this could facilitate the detection of cells with potential transformation into an HSIL. These conclusions allow us to consider the importance of strict follow-up of patients with LSIL with HR-HPV alone or with MI, which also would allow the evaluation of the prognostic value of miR-16-1.

Furthermore, the present study identified that the mixed or integrated HPV states exhibited a significant effect on the expression level of miR-16-1, in comparison with samples negative for HPV $(\mathrm{P}<0.001)$; however, the variability in the expression level of miR-16-1 has a greater explanation by the changes induced by SIL and SCC (83\%) than by the HPV physical state (33\%). In addition, when comparing women who presented with the mixed state and those with the integrated state, no significant difference was observed $(\mathrm{P}=0.105)$. A limitation of the present study was that patients who presented only with the HPV episomal physical state were not included, which could have provided additional information on the expression level of miR-16-1 compared with those with an integrated physical state. Notably, to the best of our knowledge, no studies have analyzed this relationship before. However, it has been suggested that the increased expression of miR-16-1 in CC could be due to the molecular mechanism induced by the interaction of E7 of the HPV16 and E2F (53). To demonstrate whether E7 is directly associated with the increase in the expression of miR-16-1 but not E6, a study was performed with tissue samples derived from human keratinocytes, with and without HPV16 and HPV18. The results demonstrated that on inducing the expression of E6, E7 and $\mathrm{E} 6 / \mathrm{E} 7$, the increase in the expression level of miR-16-1 was only observed in the presence of E7. This suggests that E7 was responsible for the overexpression of miR-16-1 in CC cells. In addition, by silencing the expression of E7 by small interfering RNA in CaSki (HPV16) and HeLa (HPV18) cell lines, it was demonstrated that E7-knockdown decreased the expression of miR-16-1 in comparison with the control cells (22).

It has been reported that HPV16 possesses an integration site in chromosome 13q14 (60), where the DLEU2 gene is localized, and this could activate the transcription of miR-16-1 (61). It has also been reported that HPV18 contains an integration site on chromosome 8q23-24, near the c-Myc gene $(62,63)$, which is known to be able to activate the DLEU2 gene and induce the transcription of miR-16-1 (64). The overexpression of miR-16-1 has been found to be associated with the activation of genes implicated in cellular proliferation, such as CDK6, CDC27, CARD10, C10orf46 (23), CDC7 (21) and CCNE1 (9). Additionally, E6, on degrading into p53, inhibits the expression of kinase-inhibitor proteins (55), generating an uncontrolled environment for the proliferation and immortalization of cancerous cells.

In conclusion, the present results demonstrated that the increased expression of miR-16-1 was associated with increased cellular proliferation of HSIL and SCC in the presence of the integrated state of the HR-HPV DNA alone or in MI. This suggests that the expression level of miR-16-1 could serve as an additional tool in the diagnosis of HSIL that exhibits potential progression to SCC. Therefore, follow-up studies on a larger scale are required in order to examine the clinical usefulness of the expression of miR-16-1 as a prognostic biomarker of SIL, particularly in women with a diagnosis of LSIL and the integrated state of the HR-HPV, which can later progress to HSIL.

\section{Acknowledgements}

The authors would like to thank the pathologist Dr Marco Antonio Jiménez-López (State Institute of Cancerology, 'Arturo Beltrán Ortega', Acapulco, Mexico) for contributing to the histopathological diagnoses of squamous cell carcinoma. The authors would also like to thank colposcopist gynecologist Dr Raúl Peralta-Catalán (Dysplasia Clinic, General Hospital, 'Raymundo Abarca Alarcón', Chilpancingo, Mexico) for contributing to the diagnoses of low-grade squamous intraepithelial lesions.

\section{Funding}

This study was financially supported by grant from CONACyT of the Sectoral Fund for Research in Health and Social Security (grant no. 201579), Mexico.

\section{Availability of data and materials}

The datasets used and/or analyzed during the present study are available from the corresponding author on reasonable request.

\section{Authors' contributions}

LDCAR and EILBP designed and supervised the research. LDCAR performed the cytological diagnosis. BIA carried out the molecular diagnosis of the HPV. YCC and HJW collected 
the samples and the survey data. MIZG conducted the extraction of the RNA for reverse transcription-quantitative PCR. KIGP carried out the liquid-based cytology for in situ hybridization with amplification with tyramide. EFA performed the statistical analysis. MIZG, LDCAR and EFA wrote and revised the manuscript. All authors read and approved the manuscript.

\section{Ethics approval and consent to participate}

All patients signed an informed consent for the use of their cervical samples and clinical information, and this study was approved by the Bioethics Committee at the Autonomous University of Guerrero, Guerrero, Mexico (approval no. CB-003/2018).

\section{Patient consent for publication}

Not applicable.

\section{Competing interests}

The authors declare that they have no competing interests.

\section{References}

1. Bray F, Ferlay J, Soerjomataram I, Siegel RL, Torre LA and Jemal A: Global cancer statistics 2018: GLOBOCAN estimates of incidence and mortality worldwide for 36 cancers in 185 countries. CA Cancer J Clin 68: 394-424, 2018.

2. Bulk S, Berkhof J, Bulkmans NWJ, Zielinski GD, Rozendaal L, Van Kemenade FJ, Snijders PJF and Meijer CJLM: Preferential risk of HPV16 for squamous cell carcinoma and of HPV18 for adenocarcinoma of the cervix compared to women with normal cytology in The Netherlands. Br J Cancer 94: 171-175, 2006.

3. Serrano B, de Sanjosé S, Tous S, Quiros B, Muñoz N, Bosch X and Alemany L: Human papillomavirus genotype attribution for HPVs $6,11,16,18,31,33,45,52$ and 58 in female anogenital lesions. Eur J Cancer 51: 1732-1741, 2015.

4. Jiménez-Wences H, Peralta-Zaragoza O and Fernández-Tilapa G: Human papillomavirus, DNA methylation and microRNA expression in cervical cancer (Review). Oncol Rep 31: 2467-2476, 2014.

5. Nayar R and Wilbur DC: The Bethesda system for reporting cervical cytology. Definitions, criteria, and explanatory notes. Springer International Publishing (3rd edition.), Switzerland, 2015.

6. Ferber MJ, Thorland EC, Brink AA, Rapp AK, Phillips LA McGovern R, Gostout BS, Cheung TH, Chung TKH, Fu WY and Smith DI: Preferential integration of human papillomavirus type 18 near the c-myc locus in cervical carcinoma. Oncogene 22: 7233-7242, 2003.

7. Schmitz M, Driesch C, Jansen L, Runnebaum IB and Dürst M: Non-random integration of the HPV genome in cervical cancer. PLoS One 7: e39632, 2012.

8. Medina PP and Slack FJ: MicroRNAs and cancer: An overview. Cell Cycle 7: 2485-2492, 2008.

9. Zubillaga-Guerrero MI, Alarcón-Romero LC, Illades-Aguiar B, Flores-Alfaro E, Bermúdez-Morales VH, Deas J and Peralta-Zaragoza O: MicroRNA miR-16-1 regulates CCNE1 (cyclin E1) gene expression in human cervical cancer cells. Int J Clin Exp Med 8: 15999-16006, 2015.

10. Park S, Eom K, Kim J, Bang H, Wang HY, Ahn S, Kim G, Jang H, Kim S, Lee D, et al: MiR-9, miR-21, and miR-155 as potential biomarkers for HPV positive and negative cervical cancer. BMC Cancer 17: 658, 2017.

11. Lv KT, Liu Z, Feng J, Zhao W, Hao T, Ding WY, Chu JP and Gao LJ: miR-22-3p regulates cell proliferation and inhibits cell apoptosis through targeting the eIF4EBP3 gene in human cervical cancer squamous carcinoma cells. Int J Med Sci 15: 142-152, 2018

12. Li C, Zheng X, Li W, Bai F, Lyu J and Meng QH: Serum miR-486-5p as a diagnostic marker in cervical cancer: With investigation of potential mechanisms. BMC Cancer 18: 61, 2018.

13. Li Z, Peng Z, Gu S, Zheng J, Feng D, Qin Q and He J: Global analysis of miRNA-mRNA interaction network in breast cancer with brain metastasis. Anticancer Res 37: 4455-4468, 2017.
14. Mourad L, El-Ahwany E, Zoheiry M, Abu-Taleb H, Hassan M, Ouf A, Rahim AA, Hassanien M and Zada S: Expression analysis of liver-specific circulating microRNAs in $\mathrm{HCV}$-induced hepatocellular carcinoma in Egyptian patients. Cancer Biol Ther 19: 400-406, 2018

15. Lui WO, Pourmand N, Patterson BK and Fire A: Patterns of known and novel small RNAs in human cervical cancer. Cancer Res 67: 6031-6043, 2007.

16. Lee JW, Choi CH, Choi JJ, Park YA, Kim SJ, Hwang SY, Kim WY, Kim TJ, Lee JH, Kim BG, et al: Altered microRNA expression in cervical carcinomas. Clin Cancer Res 14: 2535-2542, 2008.

17. Wang X, Tang S, Le SY, Lu R, Rader JS, Meyers C and Zheng ZM: Aberrant expression of oncogenic and tumor suppressive microRNAs in cervical cancer is required for cancer cell growth. PLoS One 3: e2557, 2008.

18. Pereira PM, Marques JP, Soares AR, Carreto L and Santos MAS: microRNA expression variability in human cervical tissues. PLoS One 5: e11780, 2010.

19. Wilting SM, Snijders PJ, Verlaat W, Jaspers A, van de Wiel MA, van Wieringen WN, Meijer GA, Kenter GG, Yi Y, le Sage C, et al: Altered microRNA expression associated with chromosomal changes contributes to cervical carcinogenesis. Oncogene 32: 106-116, 2013.

20. Wang X, Wang HK, Li Y, Hafner M, Banerjee NS, Tang S, Briskin D, Meyers C, Chow LT, Xie X, et al: microRNAs are biomarkers of oncogenic human papillomavirus infections. Proc Natl Acad Sci USA 111: 4262-4267, 2014.

21. Calin GA, Cimmino A, Fabbri M, Ferracin M, Wojcik SE, Shimizu M, Taccioli C, Zanesi N, Garzón R, Aqeilan RI, et al: miR-15a and miR-16-1 cluster functions in human leukemia. Proc Natl Acad Sci USA 105: 5166-5171, 2008.

22. Zheng ZM and Wang X: Regulation of cellular miRNA expression by human papillomaviruses. Biochim Biophys Acta 1809: 668-677, 2011.

23. Linsley PS, Schelter J, Burchard J, Kibukawa M, Martin MM, Bartz SR, Johnson JM, Cummins JM, Raymond CK, Dai H, et al: Transcripts targeted by the microRNA-16 family cooperatively regulate cell cycle progression. Mol Cell Biol 27: 2240-2252, 2007.

24. Williams JR: The declaration of Helsinki and public health. Bull World Health Organ 86: 650-652, 2008.

25. Benedet JL, Bender H, Jones H III, Ngan HY and Pecorelli S: FIGO staging classifications and clinical practice guidelines in the management of gynecologic cancers. FIGO Committee on Gynecologic Oncology. Int J Gynaecol Obstet 70: 209-262, 2000.

26. Leonard DG, Michael KW and James BF: Basics methods in Molecular Biology. McGraw-Hill Professional (2nd edition.) Appleton and Lange, Norwalk, CT, USA, 1994.

27. Livak KJ and Schmittgen TD: Analysis of relative gene expression data using real-time quantitative PCR and the 2(-Delta Delta C(T)) method. Methods 25: 402-408, 2001.

28. Wong L, Lee K, Russell I and Chen C: Endogenous controls for real-time quantitation of miRNA Using TaqMan ${ }^{\circledR}$ MicroRNA Assays. Application note TaqMan ${ }^{\circledR}$ MicroRNA Assays. Applied Biosystems, 2007.

29. Palacio-Mejía LS, Lazcano-Ponce E, Allen-Leigh B and Hernández-Avila M: Regional differences in breast and cervical cancer mortality in Mexico between 1979-2006. Salud Publica Mex 51 (Suppl 2): S208-S219, 2009 (In Spanish).

30. Secretaría de Salud: Información estadística. Estadísticas de cáncer cervicouterino, https://www.gob.mx/cms/uploads/attachment/file/12951/MortalidadCaCu2000a2013.pdf (accessed on 22/03/2020).

31. Illades-Aguiar B, Alarcón-Romero Ldel C, Antonio-Véjar V, Zamudio-López N, Sales-Linares N, Flores-Alfaro E, Fernández-Tilapa G, Vénces-Velázquez A, Muñoz-Valle JF and Leyva-Vázquez MA: Prevalence and distribution of human papillomavirus types in cervical cancer, squamous intraepithelial lesions, and with no intraepithelial lesions in women from Southern Mexico. Gynecol Oncol 117: 291-296, 2010.

32. Ortiz-Ortiz J, Alarcón-Romero Ldel C, Jiménez-López MA, Garzón-Barrientos VH, Calleja-Macías I, Barrera-Saldaña HA, Leyva-Vázquez MA and Illades-Aguiar B: Association of human papillomavirus 16 E6 variants with cervical carcinoma and precursor lesions in women from Southern Mexico. Virol J 12: $29,2015$.

33. Shen Y, Gong JM, Li YQ, Gong YM, Lei DM, Cheng GM and Li XF: Epidemiology and genotype distribution of human papillomavirus (HPV) in women of Henan Province, China. Clin Chim Acta 415: 297-301, 2013. 
34. Lacobone AD, Bottari F, Radice D, Preti EP, Franchi D, Vidal-Urbinati AM, Boveri S, Passerini R and Sandri MT: Distribution of high-risk human papillomavirus genotypes and multiple infections in preneoplastic and neoplastic cervical lesions of unvaccinated women: A cross-sectional study. J Low Genit Tract Dis 23: 259-264, 2019.

35. Li M, Du X, Lu M, Zhang W, Sun Z, Li L, Ye M, Fan W, Jiang S, Liu A, et al: Prevalence characteristics of single and multiple HPV infections in women with cervical cancer and precancerous lesions in Beijing, China. J Med Virol 91: 473-481, 2019.

36. Chaturvedi AK, Katki HA, Hildesheim A, Rodríguez AC, Quint W, Schiffman M, Van Doorn LJ, Porras C, Wacholder S, González P, et al: Human papillomavirus infection with multiple types: Pattern of coinfection and risk of cervical disease. J Infect Dis 203: 910-920, 2011.

37. Vinokurova S, Wentzensen N, Kraus I, Klaes R, Driesch C Melsheimer P, Kisseljov F, Dürst M, Schneider A and von Knebel Doeberitz M: Type dependent integration frequency of human papillomavirus genomes in cervical lesions. Cancer Res 68: 307-313, 2008

38. Evans MF, Mount SL, Beatty BG, Cooper K and Phil D: Biotinyl-tyramide-based in situ hybridization signal patterns distinguish human papillomavirus type and grade of cervical intraepithelial neoplasia. Mod Pathol 15: 1339-1347, 2002.

39. Vega-Peña A, Illades-Aguiar B, Flores-Alfaro E, López-Bayghen E, Leyva-Vázquez MA,Castañeda-SaucedoEand Alarcón-Romero LC: Risk of progression of early cervical lesions is associated with integration and persistence of HPV-16 and expression of E6, Ki-67, and telomerase. J Cytol 30: 226-232, 2013.

40. Tagle DK, Sotelo DH, Illades-Aguiar B, Leyva-Vazquez MA, Alfaro EF, Coronel YC, Hernández Odel M and Romero Ldel C: Expression of E6, p53 and p21 proteins and physical state of HPV16 in cervical cytologies with and without low grade lesions. Int J Clin Exp Med 7: 186-193, 2014.

41. Torres-Rojas FI, Alarcón-Romero LCD, Leyva-Vázquez MA, Ortiz-Ortiz J, Mendoza-Catalán MA, Hernández-Sotelo D, Del Moral-Hernández O, Rodríguez-Ruiz HA, Leyva-Illades D, Flores-Alfaro E and Illades-Aguiar B: Methylation of the L1 gene and integration of human papillomavirus 16 and 18 in cervical carcinoma and premalignant lesions. Oncol Lett 15: 2278-2286, 2018.

42. Zubillaga-Guerrero MI, Illades-Aguiar B, Leyva-Vazquez MA Flores-Alfaro E, Castañeda-Saucedo E, Muñoz-Valle JF and Alarcón-Romero LC: The integration of HR-HPV increases e expression of cyclins $\mathrm{A}$ and $\mathrm{E}$ in cytologies with and without low-grade lesions. J Cytol 30: 1-7, 2013.

43. Cricca M, Venturoli S, Leo E, Costa S, Musiani M and Zerbini M: Molecular analysis of HPV 16 E6I/E6II spliced mRNAs and correlation with the viral physical state and the grade of the cervical lesion. J Med Virol 81: 1276-1282, 2009.

44. Saunier M, Monnier-Benoit S, Mauny F, Dalstein V, Briolat J, Riethmuller D, Kantelip B, Schwarz E, Mougin C and Prétet JL: Analysis of human papillomavirus type 16 (HPV16) DNA load and physical state for identification of HPV16-infected women with high-grade lesions or cervical carcinoma. J Clin Microbiol 46: 3678-3685, 2008.

45. Ibragimova M, Tsyganov M, Shpileva O, Churuksaeva O, Bychkov V, Kolomiets L and Litviakov N: HPV status and its genomic integration affect survival of patients with cervical cancer. Neoplasma 65: 441-448, 2018.

46. Kim J, Kim K, Jeon DS, Lee CH, Roh JW, Kim Y and Park SY: Type-specific viral load and physical state of HPV type 16,18, and 58 as diagnostic biomarkers for high-grade squamous intraepitelial lesions or cervical cancer. Cancer Res Treat 52: 396-405, 2020.

47. Gallo G, Bibbo M, Bagella L, Zamparelli A, Sanseverino F, Giovagnoli MR, Vecchione A and Giordano A: Study of viral integration of HPV-16 in young patients with LSIL. J Clin Pathol 56: 532-536, 2003
48. Kulmala SMA, Syrjänen SM, Gyllensten UB, Shabalova IP, Petrovichev N, Tosi P, Syrjänen KJ and Johansson BC: Early integration of high copy HPV16 detectable in women with normal and low grade cervical cytology and histology. J Clin Pathol 59: 513-517, 2006.

49. Peitsaro P, Johansson B and Syrjänen S: Integrated human papillomavirus type 16 is frequently found in cervical cancer precursors as demonstrated by a novel quantitative real-time PCR technique. J Clin Microbiol 40: 886-891, 2002.

50. Chaiwongkot A, Vinokurova S, Pientong C, Ekalaksananan T, Kongyingyoes B, Kleebkaow P, Chumworathayi B, Patarapadungkit N, Reuschenbach M and von Knebel Doeberitz M: Differential methylation of E2 binding sites in episomal and integrated HPV 16 genomes in preinvasive and invasive cervical lesions. Int J Cancer 132: 2087-2094, 2013.

51. Schickel R, Boyerinas B, Park SM and Peter ME: MicroRNAs: Key players in e immune system, differentiation, tumorigenesis and cell death. Oncogene 27: 5959-5974, 2008.

52. Bueno MJ and Malumbres M: MicroRNAs and the cell cycle. Biochim Biophys Acta 1812: 592-601, 2011

53. Ofir M, Hacohen D and Ginsberg D: MiR-15 and miR-16 are direct transcriptional targets of E2F1 at limit E2F-induced proliferation by targeting cyclin E. Mol Cancer Res 9: 440-447, 2011.

54. Gonzalez SL, Stremlau M, Basile JR and Münger K: Degradation of the retinoblastoma tumor suppressor by the human papillomavirus type 16 E7 oncoprotein is important for functional inactivation and is separable from proteasomal degradation of E7. J Virol 75: 7583-7591, 2001

55. Nguyen CL and Münger K: Direct association of the HPV16 E7 oncoprotein with cyclin A/CDK2 and cyclin E/CDK2 complexes. Virology 380: 21-25, 2008.

56. Ohtani K, DeGregori J and Nevins JR: Regulation of the cyclin E gene by transcription factor E2F1. Proc Natl Acad Sci USA 92: 12146-12150, 1995.

57. Wang F, Fu XD, Zhou Y and Zhang Y: Down-regulation of the cyclin E1 oncogene expression by microRNA-16-1 induces cell cycle arrest in human cancer cells. BMB Rep 42: 725-730, 2009.

58. Pett $\mathrm{M}$ and Coleman $\mathrm{N}$ : Integration of high-risk human papillomavirus: A key event in cervical carcinogenesis? J Pathol 212: 356-367, 2007.

59. Kalantari M, Blennow E, Hagmar B and Johansson B: Physical state of HPV16 and chromosomal mapping of the integrated form in cervical carcinomas. Diagn Mol Pathol 10: 46-54, 2001.

60. Thorland EC, Myers SL, Gostout BS and Smith DI: Common fragile sites are preferential targets for HPV16 integrations in cervical tumors. Oncogene 22: 1225-1237, 2003.

61. Calin GA, Dumitru CD, Shimizu M, Bichi R, Zupo S, Noch E, Aldler H, Rattan S, Keating M, Rai K, et al: Frequent deletions and down-regulation of micro-RNA genes miR15 and miR16 at 13 q14 in chronic lymphocytic leukemia. Proc Natl Acad Sci USA 99: 15524-15529, 2002.

62. Popescu NC, DiPaolo JA and Amsbaugh SC: Integration sites of human papillomavirus 18 DNA sequences on HeLa cell chromosomes. Cytogenet Cell Genet 44: 58-62, 1987.

63. Chang TC, Yu D, Lee YS, Wentzel EA, Arking DE, West KM, Dang CV, Thomas-Tikhonenko A and Mendell JT: Widespread microRNA repression by Myc contributes to tumorigenesis. Nat Genet 40: 43-50, 2008

64. Lerner M, Harada M, Loven J, Castro J, Davis Z, Oscier D, Henriksson M, Sangfelt O, Grander D and Corcoran MM: DLEU2, frequently deleted in malignancy, functions as a critical host gene of the cell cycle inhibitory microRNAs miR-15a and miR-16-1. Exp Cell Res 315: 2941-2952, 2009.

This work is licensed under a Creative Commons Attribution-NonCommercial-NoDerivatives 4.0 International (CC BY-NC-ND 4.0) License. 